MEDIA ILMIAH TEKNIK SIPIL

Volume 9 Nomor 2 Juni 2021

Hal. 92-101

\title{
ANALISIS KINERJA RUAS JALAN AKIBAT ADANYA PUSAT PERBELANJAAN (STUDI KASUS KPD SWALAYAN JALAN RAJAWALI PALANGKA RAYA)
}

\author{
ANALYSIS OF ROAD PERFORMANCE DUE TO SHOPPING CENTERS (CASE STUDY KPD \\ SWALAYAN RAJAWALI ROADS PALANGKA RAYA)
}

\author{
Norce Lumbantoruan $^{* 1}$, Murniati ${ }^{2}$, Salonten ${ }^{3}$ \\ ${ }^{1}$ Mahasiswa, Program Studi Teknik Sipil, Universitas Palangka Raya \\ ${ }^{2,3}$ Dosen, Program Studi Teknik Sipil, Universitas Palangka Raya \\ *Korespondensi: norce.chikudo@gmail.com
}

\begin{abstract}
ABSTRAK
Palangka Raya merupakan pusat perekonomian Provinsi Kalimantan Tengah, yang terdapat banyak pusat perbelanjaan yang menawarkan barang dengan harga murah, salah satunya Koperasi Persekutuan Dayak Swalayan yang menjual kebutuhan sehari-hari dengan harga murah dan selalu dikunjungi oleh konsumen sehingga terjadi peningkatan tarikan lalu lintas dan cenderung mengakibatkan konflik terhadap lalu lintas yang berada tepat di depan KPD Swalayan. Dalam penelitian ini menggunakan dua data yaitu data sekunder dan data primer yang dianalisis menggunakan metode PKJI 2014. Dari hasil analisis persentase tarikan lalu lintas akibat adanya KPD Swalayan membebani ruas Jalan Rajawali sebesar 4,34\%, keberadaan KPD Swalayan mengakibatkan terjadi perubahan kinerja ruas jalan berdasarkan nilai Derajat Kejenuhan $\left(D_{J}\right)=0,60$, Kapasitas $(C)=1859,70 \mathrm{skr} / \mathrm{jam}$ sebelum KPD Swalayan beroperasi, setelah KPD Swalayan beroperasi Derajat Kejenuhan $\left(D_{J}\right)=0,57$, Kapasitas $(C)=1859,70 \mathrm{skr} / \mathrm{jam}$, dan jika KPD Swalayan dianggap tidak ada maka hambatan samping yang terjadi akan berkurang sehingga Derajat Kejenuhan $\left(D_{J}\right)=0,55$, Kapasitas $(C)=1921,69 \mathrm{skr} / \mathrm{jam}$.
\end{abstract}

Kata Kunci: Derajat Kejenuhan, Kapasitas, Kinerja Ruas Jalan

\begin{abstract}
Palangka Raya is the economic center of Central Kalimantan Province, where there are many shopping centers that offer goods at low prices, one of which is the Koperasi Persekutuan Dayak Swalayan which sells daily necessities at low prices and is always visited by consumers so that there is an increase in traffic and tends to result in increased traffic conflict over traffic that is right in front of KPD Swalayan. In this study using two data, namely secondary data and primary data which were analyzed using the PKJI 2014 method. From the results of the analysis of the the percentage of traffic pull due to the KPD Swalayan burdening Jalan Rajawali by $4.34 \%$, the existence of KPD Swalayan results in changes in the performance of roads based on the Degree of Saturation $(D J)=0,60$, Capacity $(C)=1859,70$ skr/hour before KPD Swalayan operates after KPD Swalayan operates Degree of saturation $(D J)=0,57$, Capacity $(C)=1859,70$ skr/hour, and if the KPD Swalayan is considered non-existent then the side barriers that occur will be reduced so that the Degree of Saturation (DJ) $=0,55$, Capacity $(C)=1921,69$ skr/hour.
\end{abstract}

Keywords: Degree of Saturation, Capacity, Performance of Roads 
Analisis Kinerja Ruas.., Norce Lumbantoruan ${ }^{(1)}$, Murniati $^{(2)}{ }^{\text {Salonten }}{ }^{(3)}$

\section{PENDAHULUAN}

Kota Palangka Raya merupakan salah satu kota yang memiliki andil dalam pertumbuhan perekonomian Provinsi Kalimantan Tengah. Perkembangan jumlah penduduk seiring dengan pertumbuhan ekonomi menimbulkan kebutuhan sandang dan pangan semakin besar, oleh karena itu semakin banyak pusat perbelanjaan yang akan didirikan untuk memenuhi kebutuhan hidup. Dengan meningkatnya perkembangan pusat perbelanjaan akan mengakibatkan peningkatan sarana transportasi, karena transportasi merupakan alat pendukung perekonomian seperti mobil dan sepeda motor sehingga akan terjadi peningkatan jumlah pergerakan dalam bentuk volume lalu lintas yang berakibat pada turunnya tingkat pelayanan pada jam-jam tertentu.

Pusat perbelanjaan Koperasi Persekutuan Dayak (KPD) Swalayan yang terletak di Jalan Rajawali menjual berbagai kebutuhan sehari-hari dengan harga relatif murah dibandingkan warung dan setiap hari selalu dikunjungi konsumen. Berdasarkan pengamatan awal, keberadaan pusat perbelanjaan tersebut menimbulkan jumlah tarikan perjalanan yang cukup besar. Tarikan perjalanan ini dapat mempengaruhi kinerja pelayanan jalan seperti peningkatan volume kendaraan yang akan dilewati di sepanjang ruas jalan tersebut. Terlebih lagi lokasi geometrik KPD Swalayan berada dekat dengan persimpangan jalan, yang sering kali menjadi sumber konflik lalu lintas dan rawan terhadap kecelakaan. Konflik yang ditimbulkan antara kendaraan dengan kendaraan lainnya ataupun antara kendaraan dengan pejalan kaki dapat mempengaruhi kinerja ruas Jalan Rajawali. Pada KPD Swalayan juga terjadi aktivitas bongkar muat barang di depan toko, keluar masuknya kendaraan dari lokasi parkir pertokoan dan angkutan umum yang menurunkan penumpang serta pejalan kaki akan memberikan dampak langsung terhadap ruas Jalan Rajawali.

\section{Tujuan Penelitian}

Tujuan dari penelitian ini adalah:

1. Mengetahui persentase tarikan lalu lintas yang membebani ruas jalan akibat adanya KPD Swalayan.

2. Mengetahui kinerja ruas jalan akibat adanya KPD Swalayan.

\section{Batasan Masalah}

Agar pembahasan lebih terarah dan dan tidak menyimpang dari rumusan masalah yang ditinjau maka batasan-batasan yang diambil dalam penelitian ini adalah sebagai berikut:

1. Dasar Lokasi penelitian di ruas Jalan Rajawali depan KPD Swalayan dengan panjang segmen jalan $200 \mathrm{~m}$.

2. Penelitian ini membahas kinerja ruas jalan akibat adanya KPD Swalayan.

3. Penelitian ini tidak membahas mengenai parkir pada KPD Swalayan.

4. Penelitian ini tidak merencanakan bentuk geometrik di Jalan Rajawali.

5. Penelitian ini mengacu pada Pedoman Kapasitas Jalan Indonesia (PKJI) tahun 2014.

\section{TINJAUAN PUSTAKA}

\section{Bangkitan dan Tarikan Pergerakan (Trip Generation)}

Bangkitan pergerakan adalah tahapan pemodelan yang memperkirakan jumlah pergerakan yang berasal dari suatu zona atau tata guna lahan dan tarikan pergerakan adalah jumlah pergerakan yang tertarik ke suatu tata guna lahan atau zona tarikan pergerakan (Tamin, Perencanaan dan Pemodelan Transportasi, 2000).

\section{Jalan Perkotaan}

Jalan Perkotaan adalah segmen jalan yang mempunyai perkembangan permanen dan menerus di sepanjang atau hampir seluruh segmen jalan, minimal pada satu sisinya, berupa pengembangan koridor, berada dalam atau dekat pusat perkotaan yang memiliki penduduk lebih dari 100.000 jiwa, atau dalam daerah perkotaan dengan penduduk kurang dari 100.000 jiwa tetapi mempunyai perkembangan di sisi jalannya yang permanen dan menerus (PKJI, 2014).

\section{Kriteria Kelas Hambatan Samping}

Hambatan samping adalah kegiatan di samping segmen jalan yang berpengaruh terhadap kinerja lalu lintas, seperti pejalan kaki, angkutan umum dan kendaraan lain yang berhenti, kendaraan lambat, dan kendaraan masuk dan keluar dari lahan di samping jalan (PKJI, 2014). Pembobotan dan 
Analisis Kinerja Ruas.., Norce Lumbantoruan ${ }^{(1)}$, Murniati $^{(2)}$, Salonten ${ }^{(3)}$

kriteria kelas hambatan samping ditentukan berdasarkan Tabel 1 dan Tabel 2 berikut:

Tabel 1. Pembobotan Hambatan Samping Jenis hambatan samping utama Bobot

Pejalan kaki di badan jalan dan yang menyeberang

Kendaraan umum dan kendaraan

lainnya yang berhenti

Kendaraan keluar/masuk sisi atau

lahan samping jalan

Arus kendaraan lambat (kendaraan tak bermotor)

Sumber: PKJI (2014)

Tabel 2. Kriteria Kelas Hambatan Samping

\begin{tabular}{|c|c|c|}
\hline $\begin{array}{c}\text { Kelas } \\
\text { hambatan } \\
\text { samping }\end{array}$ & $\begin{array}{l}\text { Nilai frekuensi } \\
\text { kejadian (di } \\
\text { kedua sisi) di } \\
\text { kali bobot }\end{array}$ & Ciri-ciri khusus \\
\hline $\begin{array}{l}\text { Sangat } \\
\text { rendah, } \\
\text { SR }\end{array}$ & $<100$ & $\begin{array}{l}\text { Daerah pemukiman, } \\
\text { tersedia lingkungan } \\
\text { (frontage road })\end{array}$ \\
\hline Rendah, R & $100-299$ & $\begin{array}{c}\text { Daerah pemukiman, } \\
\text { ada beberapa } \\
\text { angkutan (angkot) }\end{array}$ \\
\hline Sedang, S & $300-499$ & $\begin{array}{l}\text { Daerah industri, ada } \\
\text { beberapa toko di } \\
\text { sepanjang sisi jalan }\end{array}$ \\
\hline Tinggi, T & $500-899$ & $\begin{array}{c}\text { Daerah komersial, } \\
\text { ada aktivitas sisi } \\
\text { jalan yang tinggi }\end{array}$ \\
\hline $\begin{array}{c}\text { Sangat } \\
\text { Tinggi, ST }\end{array}$ & $>900$ & $\begin{array}{c}\text { Daerah komersial, } \\
\text { ada aktivitas pasar } \\
\text { sisi jalan }\end{array}$ \\
\hline
\end{tabular}

Sumber: PKJI (2014)

\section{Volume Lalu Lintas}

Volume lalu lintas adalah jumlah kendaraan yang melewati suatu titik ruas/segmen jalan selama interval waktu tertentu. Menurut PKJI (2014) dilakukan penyeragaman satuan dari beberapa tipe kendaraan menjadi satuan kendaraan ringan (skr), dengan menggunakan ekuivalen kendaraan ringan (ekr). Ekr untuk kendaraan ringan adalah satu dan untuk kendaraan berat serta sepeda motor ditentukan berdasarkan Tabel 3 dan Tabel 4 berikut:
Tabel 3. Ekuivalen Kendaraan Ringan Untuk Tipe Jalan 2/2TT

\begin{tabular}{|c|c|c|c|c|}
\hline \multirow{4}{*}{$\begin{array}{l}\text { Tipe } \\
\text { jalan }\end{array}$} & \multirow{4}{*}{$\begin{array}{c}\text { Arus lalu } \\
\text { lintas per } \\
\text { lajur } \\
\text { (kend/jam) }\end{array}$} & \multicolumn{3}{|c|}{ ekr } \\
\hline & & \multirow{3}{*}{ KB } & \multicolumn{2}{|c|}{ SM } \\
\hline & & & \multicolumn{2}{|c|}{$\begin{array}{l}\text { Lebar jalur lalu } \\
\text { lintas, } \mathbf{L}_{\text {jalur }}\end{array}$} \\
\hline & & & $\leq 6 \mathrm{~m}$ & $>6 \mathrm{~m}$ \\
\hline \multirow{2}{*}{$2 / 2 \mathrm{TT}$} & $<3700$ & 1,3 & 0,5 & 0,4 \\
\hline & $\geq 1800$ & 1,2 & 0,35 & 0,25 \\
\hline
\end{tabular}

Sumber: PKJI (2014)

Tabel 4. Ekuivalen Kendaraan Ringan untuk Jalan Terbagi dan Satu Arah

\begin{tabular}{cccc}
\hline Tipe jalan & $\begin{array}{c}\text { Arus lalu lintas } \\
\text { per lajur } \\
\text { (kend/jam) }\end{array}$ & \multicolumn{2}{c}{ ekr } \\
\cline { 3 - 4 } & $<1050$ & KB & SM \\
\hline 2/1, dan & $\geq 1050$ & 1,3 & 0,4 \\
4/2T & $<1100$ & 1,2 & 0,25 \\
3/1, dan & $\geq 1100$ & 1,2 & 0,4 \\
6/2D & & &
\end{tabular}

Sumber: PKJI (2014)

Analisis Kecepatan Arus Bebas $\left(\mathrm{V}_{\mathrm{B}}\right)$, Kecepatan arus bebas dapat dihitung dengan menggunakan rumus berikut:

$V_{B}=\left(V_{B D}+V_{B L}\right) \times F V_{B H S} \times F V_{B U K}$

Kecepatan arus bebas dasar $\left(\mathrm{V}_{\mathrm{BD}}\right)$, Kecepatan arus bebas dasar ditentukan berdasarkan tipe jalan dan jenis kendaraan, dapat dilihat pada Tabel 5 berikut:

Tabel 5. Kecepatan arus bebas dasar, $\mathrm{V}_{\mathrm{BD}}$

\begin{tabular}{ccccc}
\hline & \multicolumn{4}{c}{$\mathbf{V}_{\text {BD }}(\mathbf{k m} / \mathbf{j a m})$} \\
\cline { 2 - 5 } Tipe Jalan & KR & KB & SM & $\begin{array}{c}\text { Rata-rata } \\
\text { semua } \\
\text { kendaraan }\end{array}$ \\
\hline 6/2T atau 3/1 & 61 & 52 & 48 & 57 \\
4/2T atau 2/1 & 57 & 50 & 47 & 55 \\
2/2TT & 44 & 40 & 40 & 42 \\
\hline
\end{tabular}

Sumber: PKJI (2014)

Nilai penyesuaian kecepatan akibat lebar jalan $\left(\mathrm{V}_{\mathrm{BL}}\right)$, Nilai penyesuaian kecepatan arus bebas dapat ditentukan berdasarkan lebar jalur efektif dan tipe jalan, dapat dilihat pada Tabel 6 berikut: 
Analisis Kinerja Ruas.., Norce Lumbantoruan ${ }^{(1)}$, Murniati $^{(2)}$, Salonten ${ }^{(3)}$

Tabel 6. Nilai Penyesuaian Kecepatan Arus Bebas Dasar akibat Lebar Jalur Lalu Lintas Efektif, $\mathrm{V}_{\mathrm{BL}}$

\begin{tabular}{ccc}
\hline Tipe Jalan & $\begin{array}{c}\text { Lebar jalur efektif, } \\
\mathbf{L}_{\mathbf{e}}(\mathbf{m})\end{array}$ & $\begin{array}{c}\mathbf{V}_{\mathbf{B L}} \\
\mathbf{( k m / j a m})\end{array}$ \\
\hline \multirow{3}{*}{ 4/2T atau } & Per lajur & \\
Jalan satu & 3,00 & -4 \\
arah & 3,25 & -2 \\
& 3,50 & 0 \\
& 3,75 & 2 \\
& 4,00 & 4 \\
& Per lajur & \\
2/2TT & 5,00 & $-9,5$ \\
& 6,00 & -3 \\
& 7,00 & 0 \\
& 8,00 & 3 \\
& 9,00 & 4 \\
& 10,00 & 6 \\
\hline
\end{tabular}

Sumber: PKJI (2014)

Faktor penyesuaian hambatan samping (FV $\left.\mathrm{FHS}_{\mathrm{BH}}\right)$, Faktor penyesuaian kecepatan arus bebas akibat hambatan samping terbagi menjadi dua bagian yaitu jalan yang memiliki bahu, dan jalan yang dilengkapi kereb. Faktor penyesuaian hambatan samping untuk jalan berbahu, dapat dilihat pada Tabel 7 dan Faktor penyesuaian hambatan samping untuk jalan berkereb dengan jarak kereb ke penghalang terdekat, dapat dilihat pada Tabel 8 berikut:

Tabel 7. Faktor Penyesuaian Kecepatan Arus Bebas akibat Hambatan Samping, FV $_{\text {BHS }}$ untuk Jalan Berbahu dengan Lebar Efektif, $\mathrm{L}_{\mathrm{BE}}$

\begin{tabular}{|c|c|c|c|c|c|}
\hline \multirow{2}{*}{$\begin{array}{l}\text { Tipe } \\
\text { jalan }\end{array}$} & \multirow[t]{2}{*}{ KHS } & \multicolumn{4}{|c|}{$\begin{array}{c}\mathbf{F V}_{\mathrm{BHS}} \\
\mathbf{L}_{\mathrm{Be}}(\mathbf{m})\end{array}$} \\
\hline & & $\leq \mathbf{0 , 5}$ & 1,0 & 1,5 & $\geq 2$ \\
\hline \multirow{5}{*}{$4 / 2 \mathrm{~T}$} & Sangat Rendah & 1,02 & 1,03 & 1,03 & 1,04 \\
\hline & Rendah & 0,98 & 1,00 & 1,02 & 1,03 \\
\hline & Sedang & 0,94 & 0,97 & 1,00 & 1,02 \\
\hline & Tinggi & 0,89 & 0,93 & 0,96 & 0,99 \\
\hline & Sangat Tinggi & 0,84 & 0,88 & 0,92 & 0,96 \\
\hline \multirow{5}{*}{$\begin{array}{c}2 / 2 \mathrm{TT} \\
\text { atau jalan } \\
\text { satu arah }\end{array}$} & Sangat Rendah & 1,00 & 1,01 & 1,01 & 1,01 \\
\hline & Rendah & 0,96 & 0,98 & 0,99 & 1,00 \\
\hline & Sedang & 0,90 & 0,93 & 0,96 & 0,99 \\
\hline & Tinggi & 0,82 & 0,86 & 0,90 & 0,95 \\
\hline & Sangat Tinggi & 0,73 & 0,79 & 0,85 & 0,91 \\
\hline
\end{tabular}

Sumber: PKJI (2014)
Tabel 8. Faktor Penyesuaian Arus Bebas akibat Hambatan Samping untuk Jalan Berkereb dengan Jarak Kereb ke Penghalang Terdekat, $\mathrm{L}_{\mathrm{K}-\mathrm{P}}$

\begin{tabular}{|c|c|c|c|c|c|}
\hline \multirow{3}{*}{$\begin{array}{l}\text { Tipe } \\
\text { jalan }\end{array}$} & \multirow{3}{*}{ KHS } & \multicolumn{4}{|c|}{$\mathrm{FV}_{\text {BHS }}$} \\
\hline & & \multicolumn{4}{|c|}{$\mathbf{L}_{K-P}(\mathbf{m})$} \\
\hline & & $\leq \mathbf{0 , 5}$ & 1,0 & 1,5 & $\geq 2$ \\
\hline \multirow{5}{*}{$4 / 2 \mathrm{~T}$} & Sangat Rendah & 1,00 & 1,01 & 1,01 & 1,02 \\
\hline & Rendah & 0,97 & 0,98 & 0,99 & 1,00 \\
\hline & Sedang & 0,93 & 0,95 & 0,97 & 0,99 \\
\hline & Tinggi & 0,87 & 0,90 & 0,93 & 0,96 \\
\hline & Sangat Tinggi & 0,81 & 0,85 & 0,88 & 0,92 \\
\hline \multirow{5}{*}{$\begin{array}{c}2 / 2 \mathrm{TT} \\
\text { atau jalan } \\
\text { satu arah }\end{array}$} & Sangat Rendah & 0,98 & 0,99 & 0,99 & 1,00 \\
\hline & Rendah & 0,93 & 0,95 & 0,96 & 0,98 \\
\hline & Sedang & 0,87 & 0,89 & 0,92 & 0,95 \\
\hline & Tinggi & 0,78 & 0,81 & 0,84 & 0,88 \\
\hline & Sangat Tinggi & 0,68 & 0,72 & 0,77 & 0,82 \\
\hline
\end{tabular}

Faktor ukuran kota $\left(\mathrm{FV}_{\mathrm{BUK}}\right)$, Ukuran kota adalah besarnya jumlah penduduk suatu kota yang dinyatakan dalam juta jiwa. Nilai faktor ukuran kota ditentukan berdasarkan Tabel 9 berikut:

Tabel 9. Faktor Penyesuaian untuk Pengaruh Ukuran Kota pada Kecepatan Arus Bebas Kendaraan Ringan, $\mathrm{FV}_{\text {BUK }}$

\begin{tabular}{cc}
\hline $\begin{array}{c}\text { Ukuran kota (juta } \\
\text { penduduk) }\end{array}$ & $\begin{array}{c}\text { Faktor penyesuaian } \\
\text { untuk ukuran kota, } \\
\text { FV VK }_{\text {UK }}\end{array}$ \\
\hline$<0,1$ & 0,90 \\
$0,1-0,5$ & 0,93 \\
$0,5-1,0$ & 0,95 \\
$1,0-3,0$ & 1,00 \\
$>3,0$ & 1,03 \\
\hline
\end{tabular}

Sumber: PKJI (2014)

\section{Kapasitas Jalan}

Kapasitas jalan merupakan arus lalu lintas maksimum yang dapat dipertahankan per satuan waktu yang melintasi suatu titik jalan dalam kondisi tertentu. Untuk menentukan kapasitas jalan, digunakan rumus:

$\mathrm{C}=C_{o} \times F C_{L J} \times F C_{P A} \times F C_{H S} \times F C_{U K}$

Kapasitas Dasar $\left(\mathrm{C}_{\mathrm{o}}\right)$, Nilai kapasitas dasar $\left(\mathrm{C}_{\mathrm{o}}\right)$ berdasarkan tipe jalan dapat ditentukan pada Tabel 10 berikut: 
Analisis Kinerja Ruas.., Norce Lumbantoruan ${ }^{(1)}$, Murniati $^{(2)}$, Salonten ${ }^{(3)}$

Tabel 10. Kapasitas Dasar, $C_{O}$

\begin{tabular}{ccc}
\hline Tipe Jalan & $\begin{array}{c}\text { Co } \\
\text { (skr/jam) }\end{array}$ & Catatan \\
\hline $\begin{array}{c}\text { 4/2T atau jalan satu } \\
\text { arah }\end{array}$ & 1650 & $\begin{array}{c}\text { Per lajur } \\
\text { (satu arah) } \\
\text { 2/2T }\end{array}$ \\
$\begin{array}{c}\text { Per lajur } \\
\text { (dua arah) }\end{array}$ \\
\hline
\end{tabular}

Sumber: PKJI (2014)

Faktor penyesuaian pemisah arah $\left(\mathrm{FC}_{\mathrm{PA}}\right)$, Untuk jalan satu arah atau jalan dengan pembatas median memiliki faktor penyesuaian pemisah arah dengan nilai 1,00. Untuk kondisi arus lalu lintas dari kedua arah atau jalan tanpa pembatas median faktor penyesuaian pemisah arah dapat ditentukan berdasarkan Tabel 11:

Tabel 11. Faktor Penyesuaian Kapasitas Terkait Pemisah Arah Lalu Lintas, FC $_{P A}$

\begin{tabular}{cccccc}
\hline $\begin{array}{c}\text { Pemisah } \\
\text { arah }\end{array}$ & $\mathbf{5 0}$-50 & $\mathbf{5 5}-\mathbf{4 5}$ & $\mathbf{6 0}-\mathbf{4 0}$ & $\mathbf{6 5}-\mathbf{3 5}$ & $\mathbf{7 0}-\mathbf{3 0}$ \\
PA \%-\% & & & & & \\
\hline $\mathrm{FC}_{\mathrm{PA}} 2 / 2 \mathrm{TT}$ & 1,00 & 0,97 & 0,94 & 0,91 & 0,88 \\
$4 / 2 \mathrm{TT}$ & 1,00 & 0,985 & 0,97 & 0,955 & 0,94 \\
\hline \multicolumn{2}{l}{ Sumber: PKJI (2014) }
\end{tabular}

Faktor penyesuaian terkait lebar lajur atau jalur lalu lintas $\left(\mathrm{FC}_{\mathrm{LJ}}\right)$, dapat ditentukan berdasarkan Tabel 12 berikut:

Tabel 12. Faktor Penyesuaian Kapasitas akibat Perbedaan Lebar Jalur atau Jalur Lalu Lintas, $\mathrm{FC}_{\mathrm{LJ}}$

\begin{tabular}{ccc}
\hline Tipe Jalan & $\begin{array}{c}\text { Lebar jalur lalu lintas } \\
\text { efektif }\left(\mathbf{W}_{\mathbf{C}}\right),(\mathbf{m})\end{array}$ & $\mathbf{F C}_{\mathbf{L J}}$ \\
\hline \multirow{3}{*}{ Lebar per lajur } & \\
4/2T atau jalan & 3,00 & 0,92 \\
satu arah & 3,25 & 0,96 \\
& 3,50 & 1,00 \\
& 3,75 & 1,04 \\
4,00 & 1,08 \\
& Lebar jalur 2 arah & \\
$2 / 2 \mathrm{~T}$ & 5,00 & 0,56 \\
& 6,00 & 0,87 \\
& 7,00 & 1,00 \\
& 8,00 & 1,14 \\
9,00 & 1,25 \\
& 10,00 & 1,29 \\
11,00 & 1,34 \\
\hline
\end{tabular}

Sumber: PKJI (2014)

Faktor penyesuaian hambatan samping $\left(\mathrm{FC}_{\mathrm{HS}}\right)$, Faktor penyesuaian kapasitas untuk jalan berbahu dan jalan berkereb, dapat ditentukan berdasarkan Tabel 13 dan Tabel 14 berikut:

Tabel 13. Faktor Penyesuaian Kapasitas akibat KHS pada Jalan Berbahu, $\mathrm{FC}_{\mathrm{HS}}$

$$
\text { FC }_{\mathrm{HS}}
$$

\begin{tabular}{cccccc} 
& & \multicolumn{4}{c}{$\mathbf{F}_{\mathbf{H S}}$} \\
\cline { 3 - 6 } Tipe jalan & KHS & \multicolumn{4}{c}{$\begin{array}{c}\text { Lebar bahu efektif, } \mathbf{L}_{\mathbf{B e}} \\
(\mathbf{m})\end{array}$} \\
\cline { 3 - 6 } & & $\mathbf{5 0 , 5}$ & $\mathbf{1 , 0}$ & $\mathbf{1 , 5}$ & $\mathbf{2}$ \\
\hline \multirow{4}{*}{$4 / 2 \mathrm{~T}$} & $\mathrm{SR}$ & 0,96 & 0,98 & 1,01 & 1,03 \\
& $\mathrm{R}$ & 0,94 & 0,97 & 1,00 & 1,02 \\
& $\mathrm{~S}$ & 0,92 & 0,95 & 0,98 & 1,00 \\
& $\mathrm{~T}$ & 0,88 & 0,92 & 0,95 & 0,98 \\
& $\mathrm{ST}$ & 0,84 & 0,88 & 0,92 & 0,96 \\
2/2TT atau & $\mathrm{SR}$ & 0,94 & 0,96 & 0,99 & 1,01 \\
jalan satu & $\mathrm{R}$ & 0,92 & 0,94 & 0,97 & 1,00 \\
arah & $\mathrm{S}$ & 0,89 & 0,92 & 0,95 & 0,98 \\
& $\mathrm{~T}$ & 0,82 & 0,86 & 0,90 & 0,95 \\
& $\mathrm{ST}$ & 0,73 & 0,79 & 0,85 & 0,91 \\
\hline
\end{tabular}

Sumber: PKJI (2014)

Tabel 14. Faktor Penyesuaian Kapasitas akibat KHS pada Jalan Berkereb dengan Jarak dari Kereb ke Hambatan samping Terdekat sejauh $\mathrm{L}_{\mathrm{KP}}, \mathrm{FC}_{\mathrm{HS}}$

\begin{tabular}{|c|c|c|c|c|c|}
\hline \multirow{3}{*}{ Tipe jalan } & \multirow{3}{*}{ KHS } & \multicolumn{4}{|c|}{ FV $_{\text {BHS }}$} \\
\hline & & \multicolumn{4}{|c|}{$\mathbf{L}_{\mathrm{K}-\mathrm{P}}(\mathbf{m})$} \\
\hline & & $\leq 0,5$ & 1,0 & 1,5 & $\geq 2$ \\
\hline \multirow{5}{*}{$4 / 2 \mathrm{~T}$} & SR & 0,95 & 0,99 & 0,99 & 1,01 \\
\hline & $\mathrm{R}$ & 0,94 & 0,96 & 0,98 & 1,00 \\
\hline & $S$ & 0,91 & 0,93 & 0,95 & 0,98 \\
\hline & $\mathrm{T}$ & 0,86 & 0,89 & 0,92 & 0,95 \\
\hline & ST & 0,81 & 0,85 & 0,88 & 0,92 \\
\hline \multirow{5}{*}{$\begin{array}{l}\text { 2/2TT atau } \\
\text { jalan satu } \\
\text { arah }\end{array}$} & SR & 0,93 & 0,95 & 0,97 & 0,99 \\
\hline & $\mathrm{R}$ & 0,90 & 0,92 & 0,95 & 0,97 \\
\hline & $S$ & 0,86 & 0,88 & 0,91 & 0,94 \\
\hline & $\mathrm{T}$ & 0,78 & 0,81 & 0,84 & 0,88 \\
\hline & ST & 0,68 & 0,72 & 0,77 & 0,82 \\
\hline
\end{tabular}

Faktor penyesuaian ukuran kota $\left(\mathrm{FC}_{\mathrm{UK}}\right)$, Faktor penyesuaian kapasitas terkait ukuran kota dapat ditentukan berdasarkan Tabel 15 berikut:

Tabel 15. Faktor Penyesuaian Kapasitas Terkait Ukuran Kota, $\mathrm{FC}_{\mathrm{UK}}$

\begin{tabular}{cc}
\hline $\begin{array}{c}\text { Ukuran kota (juta } \\
\text { penduduk) }\end{array}$ & $\begin{array}{c}\text { Faktor penyesuaian } \\
\text { untuk ukuran kota, } \\
\text { FC }_{\text {UK }}\end{array}$ \\
\hline$<0,1$ & 0,86 \\
$0,1-0,5$ & 0,90 \\
$0,5-1,0$ & 0,94 \\
$1,0-3,0$ & 1,00 \\
$>3,0$ & 1,04 \\
\hline
\end{tabular}

Sumber: PKJI (2014) 
Analisis Kinerja Ruas.., Norce Lumbantoruan ${ }^{(1)}$, Murniati $^{(2)}$, Salonten ${ }^{(3)}$

\section{Kinerja Jalan}

Kriteria kinerja lalu lintas dapat ditentukan berdasarkan nilai derajat kejenuhan $\left(D_{J}\right)$ atau kecepatan tempuh $\left(\mathrm{V}_{\mathrm{T}}\right)$ pada suatu kondisi jalan tertentu yang terkait dengan geometrik, arus lalu lintas, dan lingkungan jalan untuk kondisi eksisting maupun untuk kondisi desain. Derajat Kejenuhan (DJ), Derajat kejenuhan dapat dihitung dengan menggunakan persamaan berikut:

$\mathrm{D}_{J}=\frac{Q}{C}$

Tingkat Pelayanan, Tingkat pelayanan merupakan besarnya arus lalu lintas yang dapat dilewatkan oleh segmen tertentu dengan mempertahankan tingkat kecepatan atau derajat kejenuhan tertentu seperti pada Tabel 16 berikut:

Tabel 16. Faktor Penyesuaian Kapasitas Terkait Ukuran Kota, $\mathrm{FC}_{\mathrm{UK}}$

\begin{tabular}{|c|c|c|}
\hline $\begin{array}{c}\text { Tingkat } \\
\text { Pelayanan }\end{array}$ & Karakteristik Lalu Lintas & Dj (Q/C) \\
\hline A & $\begin{array}{c}\text { Kondisi arus lalu lintas } \\
\text { bebas dengan kecepatan } \\
\text { tinggi dan volume lalu lintas } \\
\text { rendah }\end{array}$ & $0,00-0,20$ \\
\hline B & $\begin{array}{l}\text { Arus stabil, tetapi kecepatan } \\
\text { operasi mulai dibatasi oleh } \\
\text { kondisi lalu lintas }\end{array}$ & $0,21-0,44$ \\
\hline C & $\begin{array}{c}\text { Arus lalu lintas stabil, } \\
\text { kecepatan gerak kendaraan } \\
\text { dikendalikan }\end{array}$ & $0,45-0,74$ \\
\hline D & $\begin{array}{c}\text { Arus mendekati stabil, } \\
\text { kecepatan masih dapat } \\
\text { dikendalikan, V/C masih } \\
\text { dapat ditolerir }\end{array}$ & $0,75-0,84$ \\
\hline $\mathrm{E}$ & $\begin{array}{l}\text { Arus tidak stabil, kecepatan } \\
\text { terkadang terhenti, } \\
\text { permintaan sudah mendekati } \\
\text { kapasitas }\end{array}$ & $0,85-1,00$ \\
\hline $\mathrm{F}$ & $\begin{array}{l}\text { Arus dipaksakan, kecepatan } \\
\text { rendah, volume di atas } \\
\text { kapasitas, antrean panjang } \\
\text { (macet) dan hambatan } \\
\text { samping besar }\end{array}$ & $>1,00$ \\
\hline
\end{tabular}

Sumber: PKJI (2014)

\section{METODE PENELITIAN}

\section{Lokasi Penelitian}

Penelitian ini berlokasi di Kota Palangka Raya, Kalimantan Tengah, di ruas Jalan Rajawali tepatnya di depan KPD Swalayan.

\section{Pengumpulan Data}

Dalam penelitian ini data yang digunakan terdiri dari dua jenis, yaitu :

1. Data Primer

Data primer merupakan data yang didapat langsung dari lapangan dengan melakukan survei pengamatan dan pengukuran langsung pada lokasi penelitian. Data primer yang digunakan pada untuk menganalisa data yaitu sebagai berikut :

a. Data Geometrik Jalan, didapat dengan melakukan survei lapangan dengan cara mengukur lebar jalan, lebar bahu, lebar median, yang dilakukan di depan KPD Swalayan Jalan Rajawali.

b. Data Volume Lalu Lintas, didapat dengan cara melakukan survei volume lalu lintas dan menghitung volume lalu lintas secara terklasifikasi yang lewat pada ruas jalan.

c. Data Hambatan Samping, dilakukan bersamaan dengan pengambilan data volume lalu lintas.

2. Data Sekunder

Data sekunder merupakan data yang digunakan sebagai penunjang penelitian ini yaitu data yang didapat dari literatur atau instansi terkait, yaitu jumlah penduduk di Kota Palangka Raya, peta lokasi dan dokumentasi.

\section{Bagan Alir Penelitian}

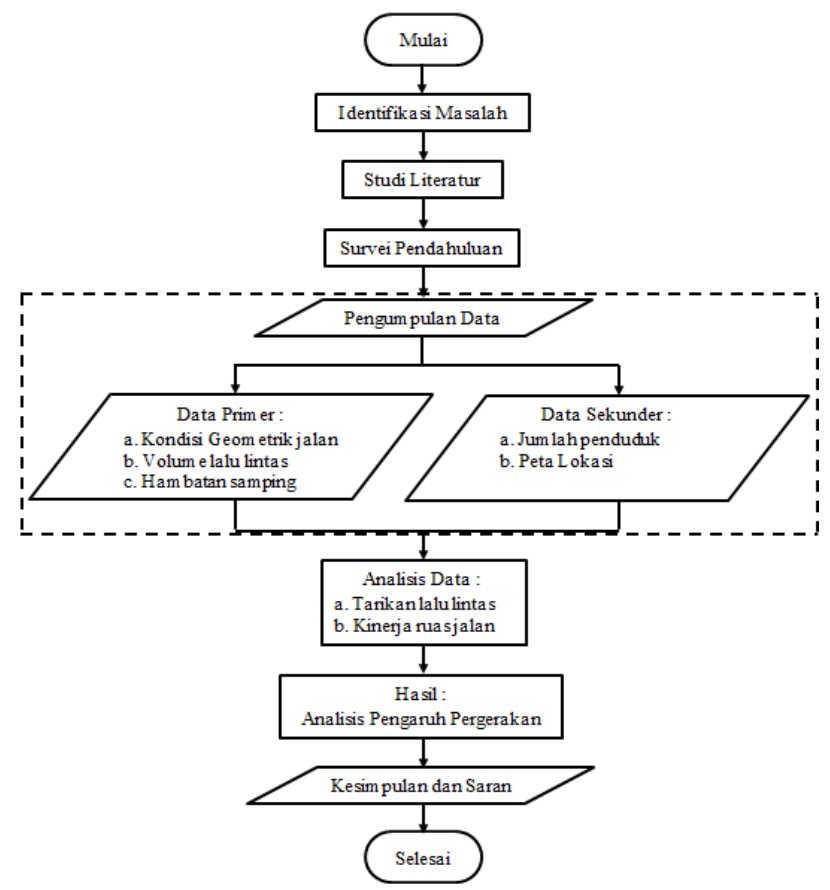

Gambar 1. Bagan Alir Penelitian 
Analisis Kinerja Ruas.., Norce Lumbantoruan ${ }^{(1)}$, Murniati $^{(2)}$, Salonten ${ }^{(3)}$

\section{Waktu Penelitian}

Penelitian dilakukan selama 1 (satu) minggu, pada hari pertama penelitian dilakukan selama 12 (dua belas) jam untuk menentukan jam puncak dan hari berikutnya dilakukan penelitian pada jam puncak pagi, siang, dan sore selama dua jam.

\section{HASIL ANALISIS DAN PEMBAHASAN}

\section{Data Primer}

Data primer yang digunakan untuk menganalisa data adalah sebagai berikut: data geometrik jalan, data volume lalu lintas, data hambatan samping.

Tabel 17. Kondisi geometrik Jalan Rajawali

\begin{tabular}{lc}
\hline \multicolumn{1}{c}{ Nama Jalan } & Jalan Rajawali \\
\hline Tipe Jalan & Jalan Sedang tipe 2/2TT \\
Panjang segmen jalan & 200 meter \\
diamati & 3 meter (Jalur A, Arah \\
Lebar jalan Efektif & Beliang) \\
& 3 meter (Jalur B, Arah \\
& Rajawali) \\
Lebar trotoar & 1,8 meter \\
Lebar drainase & 1,5 meter \\
Lebar bahu efektif & 0,8 meter \\
Rambu lalu lintas & Tidak ada \\
\hline Sumber: Hasil Pengukuran Lapangan (2019)
\end{tabular}

\section{Data Sekunder}

Data sekunder adalah data pendukung untuk data primer, dalam hal ini berupa data jumlah penduduk Kota Palangka Raya. Data ini digunakan untuk menentukan faktor penyesuaian ukuran kota.

Tabel 18. Kapasitas Dasar, $\mathrm{C}_{O}$

\begin{tabular}{ccc}
\hline Tahun & $\begin{array}{c}\text { Jumlah } \\
\text { Penduduk (Jiwa) }\end{array}$ & $\begin{array}{c}\text { Laju } \\
\text { Pertumbuhan (\%) }\end{array}$ \\
\hline 2013 & 244.500 & 2,56 \\
2014 & 252.105 & 2,51 \\
2015 & 259.865 & 2,47 \\
2016 & 267.757 & 2,34 \\
2017 & 275.667 & 2,33 \\
2018 & 283.612 & 2,24 \\
& Rata-rata & 2,41 \\
\hline
\end{tabular}

Sumber: BPS Kota Palangka Raya (2019)

\section{Volume lalu Lintas}

Data survei lalu lintas diambil selama 7 hari yaitu pada hari Senin, Selasa, Rabu, Kamis, Jumat, Sabtu dan Minggu untuk masing-masing lokasi penelitian. Data survei lalu lintas kemudian dianalisis menggunakan ketentuan PKJI 2014 untuk kapasitas jalan perkotaan dengan melihat volume lalu lintas maksimum per jam (kend/jam) pada tiap lokasi penelitian sebagai berikut:

Tabel 19. Volume Lalu Lintas Maksimum $\mathrm{Jl}$. Rajawali

\begin{tabular}{lcccccc}
\hline $\begin{array}{c}\text { Hari/ } \\
\text { Waktu }\end{array}$ & Arah & $\begin{array}{c}\text { Jenis } \\
\text { Kend. }\end{array}$ & $\begin{array}{c}\text { Data } \\
\text { ekend/ } \\
\text { (kam) }\end{array}$ & $\begin{array}{c}\text { Total } \\
\text { (skr/ } \\
\text { jam) }\end{array}$ & $\begin{array}{c}\text { Total } \\
\text { Kedua } \\
\text { Arah } \\
\text { (skr/jam) }\end{array}$ \\
\hline Sabtu, & Jl. & KR & 1 & 236 & & \\
$12 / 10 / 19$ & & KB & 1,2 & 6 & 571,85 & \\
$16.00-$ & Jl. & KR & 0,35 & 939 & & 1063,40 \\
17.00 & Rajawali & KB & 1,2 & 167 & 491,55 & \\
& & SM & 0,35 & 917 & & \\
\hline
\end{tabular}

Sumber: Hasil Analisis Data (2019)

\section{Data Hambatan Samping}

Data survei hambatan samping dilakukan bersamaan dengan survei volume lalu lintas. Data rekapitulasi total hambatan samping maksimum dapat dilihat pada Tabel 20 berikut:

Tabel 20. Hambatan Samping Maksimum

\begin{tabular}{|c|c|c|c|c|c|}
\hline $\begin{array}{c}\text { Ruas } \\
\text { Jalan/Hari/Waktu }\end{array}$ & $\begin{array}{c}\text { PED } \\
\mathbf{x} \\
(\mathbf{0 , 5})\end{array}$ & $\begin{array}{c}\text { PSV } \\
\mathbf{x} \\
(\mathbf{1 , 0})\end{array}$ & $\begin{array}{c}\text { EEV } \\
\mathbf{x} \\
(\mathbf{0 , 7})\end{array}$ & $\begin{array}{c}\text { SMV } \\
\mathbf{x} \\
(\mathbf{0 , 4})\end{array}$ & Tot \\
\hline $\begin{array}{l}\text { Rabu, 09/10/19 } \\
15.45-16.45\end{array}$ & 7,5 & 5 & 80 & 14 & 316,5 \\
\hline
\end{tabular}

Sumber: Hasil Analisis Data (2019)

Total hambatan samping maksimum untuk Jalan Rajawali sebesar 316,5 masuk dalam kelas hambatan samping Sedang (S).

Kecepatan Arus Bebas $\left(\mathrm{V}_{\mathrm{B}}\right)$, Rekapitulasi perhitungan kecepatan arus bebas $\left(\mathrm{V}_{\mathrm{B}}\right)$ dapat dilihat pada Tabel 21 berikut:

Tabel 21. Kecepatan Arus Bebas $\left(\mathrm{V}_{\mathrm{B}}\right)$

\begin{tabular}{|c|c|c|c|c|c|c|}
\hline Ruas Jalan & $\begin{array}{l}\text { Tipe } \\
\text { Jalan }\end{array}$ & $\begin{array}{l}V_{\text {BD }} \\
(\mathbf{k m} / \\
\text { jam })\end{array}$ & $\begin{array}{l}V_{\text {BL }} \\
(\mathbf{k m} / \\
\text { jam) }\end{array}$ & FV $_{\text {BHS }}$ & FV & $\begin{array}{c}V_{\text {B }} \\
(\mathbf{k m} / \\
\text { jam) }\end{array}$ \\
\hline Rajawali & $2 / 2 \mathrm{TT}$ & 44 & -3 & 0,93 & 0,93 & 35,46 \\
\hline
\end{tabular}


Analisis Kinerja Ruas.., Norce Lumbantoruan ${ }^{(1)}$, Murniati $^{(2)}$, Salonten ${ }^{(3)}$

\section{Kapasitas (C)}

Rekapitulasi perhitungan kapasitas jalan (C) dapat dilihat pada Tabel 22 berikut:

Tabel 22. Kapasitas (C)

\begin{tabular}{|c|c|c|c|c|c|c|c|}
\hline $\begin{array}{l}\text { Ruas } \\
\text { Jalan }\end{array}$ & $\begin{array}{c}\text { Tipe } \\
\text { Jalan }\end{array}$ & $\begin{array}{c}\mathrm{Co}_{0} \\
(\mathrm{~km} / \\
\text { jam})\end{array}$ & $F_{L J}$ & FC $_{\mathbf{P A}}$ & $\mathbf{F C}_{\mathbf{H S}}$ & $\mathbf{F C}_{\mathrm{UK}}$ & $\begin{array}{c}\mathrm{C} \\
(\mathbf{k m} / \\
\text { jam) }\end{array}$ \\
\hline Rajawali & $2 / 2 \mathrm{TT}$ & 2900 & 0,87 & 0,91 & 0,90 & 0,90 & 1859,70 \\
\hline
\end{tabular}

Sumber: Hasil Analisis Data (2019)

\section{Kinerja Lalu Lintas}

Rekapitulasi perhitungan derajat kejenuhan (DJ) dapat dilihat pada Tabel 23 berikut:

Tabel 23. Derajat Kejenuhan $\left(D_{\mathrm{J}}\right)$

\begin{tabular}{lcccc}
\hline Ruas Jalan & $\begin{array}{c}\text { Tipe } \\
\text { Jalan }\end{array}$ & $\mathbf{Q}$ (skr/jam) & $\begin{array}{c}\mathbf{C} \\
\text { (skr/jam) }\end{array}$ & $\mathbf{D}_{\mathbf{J}}$ \\
\hline Rajawali & $2 / 2 \mathrm{TT}$ & 1063,4 & 1859,70 & 0,57 \\
\hline
\end{tabular}

Sumber: Hasil Analisis Data (2019)

Rekapitulasi perhitungan waktu tempuh $\left(\mathrm{V}_{\mathrm{T}}\right)$ dapat dilihat pada Tabel 24 berikut:

Tabel 24. Waktu Tempuh $\left(\mathrm{W}_{\mathrm{T}}\right)$

\begin{tabular}{ccccc}
\hline $\begin{array}{c}\text { Ruas } \\
\text { Jalan }\end{array}$ & $\begin{array}{c}\text { Tipe } \\
\text { Jalan }\end{array}$ & $\begin{array}{c}\mathbf{L} \\
(\mathbf{k m})\end{array}$ & $\begin{array}{c}\mathbf{V}_{\mathbf{T}} \\
(\mathbf{k e n d} / \mathbf{j a m})\end{array}$ & $\begin{array}{c}\mathbf{W}_{\mathbf{T}} \\
(\mathbf{k e n d} / \mathbf{j a m})\end{array}$ \\
\hline Rajawali & 2/2TT & 0,1 & 29 & 0,0034 \\
\hline \multicolumn{5}{c}{ Sumber: Hasil Analisis Data (2019) }
\end{tabular}

Rekapitulasi Tingkat Pelayanan Jalan dapat dilihat pada Tabel 25 berikut :

Tabel 25. Tingkat Pelayanan Jalan

\begin{tabular}{lccccc}
\hline $\begin{array}{l}\text { Ruas } \\
\text { Jalan }\end{array}$ & $\begin{array}{c}\text { Tipe } \\
\text { Jalan }\end{array}$ & $\begin{array}{c}\text { Q } \\
\text { (skr/jam }\end{array}$ & $\begin{array}{c}\text { C } \\
\text { (skr/jam }\end{array}$ & D $_{\mathbf{J}}$ & Kategori \\
\hline Rajawali & $2 / 2 \mathrm{TT}$ & 1063,40 & 1859,70 & 0,57 & $\mathrm{C}$ \\
Tmg. & $4 / 2 \mathrm{~T}$ & 570,05 & 1270,57 & 0,45 & $\mathrm{C}$ \\
Tilung & & &
\end{tabular}

Sumber: Hasil Analisis Data (2019)

\section{Kinerja Lalu Lintas Sebelum KPD Swalayan Beroperasi}

\section{Volume lalu Lintas}

Data volume lalu lintas sebelum KPD Swalayan beroperasi dapat dilihat pada tabel berikut:
Tabel 26. Volume Lalu Lintas Maksimum Jl. Rajawali Sebelum KPD Swalayan Beroperasi

\begin{tabular}{ccccccc}
\hline $\begin{array}{c}\text { Hari/ } \\
\text { Waktu }\end{array}$ & Arah & $\begin{array}{c}\text { Jenis } \\
\text { Kend }\end{array}$ & ekr & $\begin{array}{c}\text { Data } \\
\text { (kend/ } \\
\text { jam) }\end{array}$ & $\begin{array}{c}\text { Total } \\
\text { (skr/ } \\
\text { jam) }\end{array}$ & $\begin{array}{c}\text { Total } \\
\text { Kedua } \\
\text { arah } \\
\text { (skr/jam) }\end{array}$ \\
\hline Rabu, & Bl. & KR & 1 & 308 & & \\
$09 / 10 / 19$ & & KB & 1,2 & 1 & 727,8 & \\
$06.00-$ & Jl. & KR & 0,35 & 1196 & & 1122,55 \\
07.00 & Rajawali & KB & 1,2 & 2 & 394,75 & \\
& & SM & 0,35 & 641 & & \\
\hline
\end{tabular}

Sumber: Hasil Analisis Data (2019)

\section{Data Hambatan Samping}

Data survei hambatan samping setelah KPD Swalayan beroperasi dilakukan bersamaan dengan survei volume lalu lintas. Data rekapitulasi total hambatan samping maksimum sebelum KPD Swalayan beroperasi dapat dilihat pada Tabel 27 berikut:

Tabel 27. Hambatan Samping Maksimum Sebelum KPD Swalayan Beroperasi

\begin{tabular}{llllll}
\hline \multicolumn{1}{c}{ Ruas } & \multicolumn{3}{c}{ PED PSV } & EEV & SMV \\
Jalan/Hari/Wakt & $\mathbf{x}$ & $\mathbf{x}$ & $\mathbf{x}$ & $\mathbf{x}$ t & Total \\
\multicolumn{1}{c}{$\mathbf{u}$} & $(\mathbf{0 , 5})$ & $(\mathbf{1 , 0})$ & $(\mathbf{0 , 7})$ & $(\mathbf{0 , 4})$ & \\
\hline Rajawali & & & & & \\
Selasa, 08/10/19 & 20 & 7 & 261,8 & 11,2 & 300 \\
$06.15-07.15$ & & & & & \\
\hline
\end{tabular}

Sumber: Hasil Analisis Data (2019)

Total hambatan samping maksimum untuk Jalan Rajawali sebesar 300 masuk dalam kelas hambatan samping Sedang (S).

\section{Kecepatan Arus Bebas $\left(\mathbf{V}_{\mathbf{B}}\right)$}

Rekapitulasi perhitungan kecepatan arus bebas $\left(\mathrm{V}_{\mathrm{B}}\right)$ sebelum KPD Swalayan beroperasi dapat dilihat pada Tabel 28 berikut:

Tabel 28. Rekapitulasi Kecepatan Arus Bebas $\left(\mathrm{V}_{\mathrm{B}}\right)$ Sebelum KPD Swalayan Beroperasi

\begin{tabular}{|c|c|c|c|c|c|c|}
\hline Ruas Jalan & $\begin{array}{l}\text { Tipe } \\
\text { Jalan }\end{array}$ & $\begin{array}{l}V_{\text {BD }} \\
(\mathbf{k m} / \\
\text { jam) }\end{array}$ & $\begin{array}{l}V_{\text {BL }} \\
(\mathbf{k m} / \\
\text { jam) }\end{array}$ & FV $_{\text {BHS }}$ & $\mathrm{FV}_{\text {BUK }}$ & $\begin{array}{c}V_{B} \\
(\mathbf{k m} / \\
\text { jam) }\end{array}$ \\
\hline Rajawali & $2 / 2 \mathrm{TT}$ & 44 & -3 & 0,91 & 0,93 & 34,70 \\
\hline
\end{tabular}

Sumber: Hasil Analisis Data (2019) 
Analisis Kinerja Ruas.., Norce Lumbantoruan ${ }^{(1)}$, Murniati $^{(2)}$, Salonten ${ }^{(3)}$

Derajat Kejenuhan $\left(D_{J}\right)=0,57$, Kapasitas $(C)=$ $1859,70 \mathrm{skr} / \mathrm{jam}$, Tingkat Pelayanan C, dan jika KPD Swalayan dianggap tidak ada maka hambatan samping yang terjadi akan berkurang sehingga Derajat Kejenuhan $\left(D_{\mathrm{J}}\right)=0,55$, Kapasitas $(\mathrm{C})=1921,69 \mathrm{skr} / \mathrm{jam}$, Tingkat Pelayanan C.

\section{Saran}

Berdasarkan hasil analisis dan pembahasan dapat diberikan beberapa saran sebagai berikut:

1. Dalam perencanaan pengembangan suatu kawasan atau perencanaan tata ruang suatu wilayah hendaknya selalu dihubungkan dengan perencanaan jaringan transportasi kawasan tersebut, sehingga dampak lalu lintas yang timbul dapat diminimalkan dan memudahkan dalam penanganannya.

2. Diperlukan kajian lebih lanjut setelah pukul 17.00-17.30 WIB untuk mengetahui pergerakan KPD Swalayan terhadap kinerja ruas jalan pada malam hari.

\section{DAFTAR PUSTAKA}

Anonim. (1994), Highways and Transportation, The Journal of the Institution of Highways and Transportation \& IHIE, London.

Badan Pusat Statistik (2019), Pertumbuhan Ekonomi Kalimantan Tengah Triwulan I Tahun 2019, Palangka Raya.

Departemen Pekerjaan Umum (2007), Pedoman Analisis dampak Lalu Lintas Jalan akibat Pengembangan Kawasan di Perkotaan, Jakarta.

Departmen Pekerjaan Umum (2014), Pedoman Kapasitas Jalan Indonesia 2014, Jakarta.

Direktorat Jendral Bina Marga (1990), Panduan dan Survei Perhitungan Waktu Perjalanan Lalu Lintas, Jakarta

Direktorat Jendral Bina Marga (1992), Standar Perencanaan Geometrik untuk Jalan Perkotaan, Jakarta.

Katihokang, M. F. (2016), Dampak Pusat Perbelanjaan Sakura Mart Terhadap Kinerja Ruas Jalan Trans Sulawesi Di Kota Amurang, Jurnal Sipil Statik, Vol. 4, 787-794, Manado.

Leonardo. (2016), Analisis Pengaruh Aktivitas Parkir pada Pusat Perbelanjaan terhadap Kelancaran Arus Lalu Lintas Studi Kasus Pada Mega Town Square Kota Pangkalan
Bun, Tugas Akhir Fakultas Teknik UPR, Palangka Raya.

Muwarno, D. (2003), Perencanaan Lingkungan Transportasi, Universitas Gadjah Mada, Yogyakarta.

N. Y. P. Tanjung, Sulistiyorini, R., dan Putra, S. (2016), Pengaruh Pergerakan Candra Superstore terhadap Kinerja Jaringan Jalan disekitarnya, JRSDD, Vol. 4, 215-223, Bandar Lampung.

Peraturan Menteri Perhubungan No. KM 14 Tahun 2006, Manajemen dan Rekayasa Lalu Lintas di Jalan

Peraturan Pemerintah Republik Indonesia No. 32 Tahun 2011, Manajemen dan Rekayasa Analisis Dampak, serta Manajemen Kebutuhan Lalu Lintas

Setiati, E. P. (2011), Analisis Dampak Lalu Lintas pada Pusat Perbelanjaan yang Telah Beroperasi Ditinjau Dari Tarikan Perjalanan Studi Kasus pada Megatop Trade Center Palangka Raya, Tugas Akhir Fakultas Teknik UPR, Palangka Raya.

Tamin, O. Z. (2000), Perencanaan dan Pemodelan Transportasi, Institut Teknologi Bandung, Bandung.

Undang-Undang Republik Indonesia Nomor 38 Tahun 2004, Jalan 